\title{
Germ Cell Development During Spermatogenesis and Some Characteristics of Mature Sperm Morphology in Male Scapharca subcrenata (Pteriomorphia: Arcidae) in Western Korea
}

\author{
Ee-Yung Chung ${ }^{1}$, Jin Hee $\mathrm{Kim}^{2}$, Sung Han $\mathrm{Kim}^{3}$ and Won-Jae Seo ${ }^{1}$ \\ ${ }^{1}$ Korea Marine Environment \& Ecosystem Institute, Dive Korea, Bucheon 420-857, Korea \\ ${ }^{2}$ Marine Eco-Technology Institute, Busan 608-830, Korea \\ ${ }^{3}$ Department of Aquaculture and Aquatic Sciences, Kunsan National University, Gunsan 573-701, Korea
}

\begin{abstract}
The ultrastructural characteristics of germ cell development during spermatogenesis and mature sperm morphology of in male Scapharca subcrenata were investigated by transmission electron microscope observation. Spermatogonia are located nearest the outer wall of the acinus, while spermatocytes and spermatids are positioned near the accessory cells. The accessory cells, which is in close contact with developing germ cells, contained a large quantity of glycogen particles and lipid droplets in the cytoplasm. Therefore, it is assumed that they are involved in supplying of the nutrients for germ cell development. The morphologies of the sperm nucleus and the acrosome of this species are the oval shape and cone shape, respectively. Spermatozoa are approximately $45-50 \mu \mathrm{m}$ in length including a sperm nucleus (about $1.30 \mu \mathrm{m}$ in length), an acrosome (about 0.59 $\mu \mathrm{m}$ in length), and tail flagellum (about 43-47 $\mu \mathrm{m}$ ). The axoneme of the sperm tail shows a $9+2$ structure. As some characteristics of the acrosomal vesicle structures, the right and left basal rings show electron opaque part (region), and also the anterior apex part of the acrosomal vesicle shows electron opaque part (region). These characteristics of the acrosomal vesicle were found in Acinidae and other several families in subclass Pteriomorphia. These common characteristics of the acrosomal vesicle in subclass Pteriomorphia can be used for phylogenetic and taxonomic analysis as a taxonomic key or a significant tool. The number of mitochondria in the midpiece of the sperm of this species are five, as one of common characteristics appear in most species in Arcidae and other families in subclass Pteriomorphia. The acrosomal vesicles of Arcidae species do not contain the axial rod and several transverse bands in acrosome, unlkely as seen in Ostreidae species in subclass Pteriomorphia, These characteristics can be used for the taxonomic analysis of the family or superfamily levels as a systematic key or tools.
\end{abstract}

Key words: Scapharca subcrenata, spermatogenesis, germ cell, mature sperm morphology

\section{INTRODUCTION}

Aside from their natural resource significance, the ark shells in the family Arcidae comprise one of the more taxonomically important group of bivalve molluscs. Spermatogenesis and mature sperm morphology have

Received May 29, 2011; Accepted June 20, 2011 Corresponding author: Chung, Ee-Yung

Tel: +82 (32) 328-5145 e-mail: eychung@kunsan.ac.kr $1225-3480 / 24386$ been documented in many species of bivalve molluscs using electron microscopy (Eckelbarger et al., 1990; Eckelbarger and Davis, 1996; Gaulejac et al., 1995; Chung and Ryou, 2000; Chung et al., 2000, 2007, 2010).

It is well-known that the ultrastructure of the spermatozoon in the bivalves might be related to the systematics of bivalves (Popham et al., 1974). For that reason, sperm ultrastructure has long been viewed as a tool in assessing phylogenetic relationships in the metazoa through the use of spermiocladistic analysis (Jamiesen, 1987, 1991; Franzén, 1970). To date, comprehensive studies on spermatogenesis of bivalves in 
Korea have been restricted to a few species in the familes Mytilidae (Kim et al., 2010b), Pectinidae (Chung et al., 2005), and Ostreidae (Kim et al., 2010a,b) in the subclass Pteriomorphia.

Previously, regading the ark shell, Scapharca subcrenata, there have been some studies on aspects of reproduction, including larvae and young shells (Yoshida, 1953; Tanaka, 1954), reproductive cycle (Kwun and Chung, 1999), spawning season and fatness (Hata, 1948; Tanaka, 1954; Yoo, 1964), on aspects of ecology, including growth and size (Yoshida, 1953; Yoo, 1964) and propagation (Yoshida, 1953), and on morphology (Yoo, 1977). Even though some works on reproduction, ecology and morphology have been carried out already, there are still gaps in our knowledge on reproductive biology. Little information is available on ultrastructural characteristics of germ cell development during spermatogenesis and mature sperm morpholgy of this species. In particular, the ultrastructural study on spermatogenesis and mature sperm morpholgy of Scapharca subcrenata has not been reported. Of sperm ultrastructures, the acrosome of the sperm shows morphological diversity in the bivalve sperm, and hence it may be the most useful structure in assessing phylogenetic relations (Franzén, 1956). Recently, the acrosomal morphology of the sperm has been used to organize bivalve subclasses (Popham, 1979). In association with the acrosomal morphology, Healy (1989) reported that different subclasses of bivalves each have unique acrosomal morphologies. Therefore, the acrosomal morphology of the sperm in S. subcrenata should be compared with the species of other families in subclass Pteriomorphia.

In addition, the number of mitochondria in the sperm midpiece tend to be stable within any given family or superfamily (Healy, 1989, 1995). Therefore, the number of mitochondria in sperm midpiece of this species should be investigated and compared with the same family Arcidae. Beside ultrastructures of germ cells during spermatogenesis, mature sperm morphology should be studied to clarify ultrastructural characteristic in detail.

The present study is the first to describe some taxonomic implications of mature sperm morphology of the ark shell. Therefore, the purpose of the present study is to describe the ultrastructures of germ cells during spermatogenesis and to clarify mature sperm ultrastructural differences by taxonomic analyses of $S$. sucrenata.

\section{MATERIALS AND METHODS}

\section{Sampling}

A total of 80 specimens of $S$. subcrenata were collected monthly in intertidal zone of Gomso Bay, Jollabuk-do, Korea for one year from January to December, 2006. Sexually mature specimens were used for transmission electron microscope observations.

\section{Transmission electron microscope observations}

For transmission electron microscope observations, excised pieces of ripe testis were cut into small pieces and fixed in cold $\left(0-4^{\circ} \mathrm{C}\right) 2.5 \%$ paraformaldehyde glutaraldehyde in $0.1 \mathrm{M}$ phosphate buffer solution ( $\mathrm{pH}$ 7.4) for $2 \mathrm{~h}$. Subsequently tissue pieces were washed for $30 \mathrm{~min}$. in buffer, osmicated for $80 \mathrm{~min}$. (1\% osmium tetraoxide prepared in sucrose adjusted buffer), rinsed in buffer(1h), dehydrated in ethanol (20-100\%) and finally embedded in an Epon-Araldite mixture. Ultrathin sections of Epon-embedded specimens were cut with glass knives on a LKB ultramicrotome at a thickness of about 80-100 nm. Tissue sections were mounted on collodion-coated copper grids, doubly stained with uranyl acetate followed by lead citrate, and observed with a JEM 100 CX-II (80-KV) electron microscope.

\section{RESULTS}

\section{Ultrastructure of germ cells during spermatogenesis}

The process of spermatogenesis appear to be similar to those of other bivalve species. Spermatogenesis occur in numerous acini of the testis. In the mature testis, the transition from spermatogonia to spermatozoon is observed in one section. The process of spermatogenensis appear to be similar to other bivalves. Spermatogenesis occur in the acini of the testis can be divided into four stages as follows: (1) spermatogonia, (2) spermatocytes, (3) spermatids and (4) spermatozoa.

Spermatogonia: As observed in other bivalves, spermatogonia appear in this stage. Spermatogonia are 
6-7.5 $\mu \mathrm{m}$ diameter each with a spherical nucleus (approximately $3.7 \mu \mathrm{m}$ diameter). The nucleus contains small clumps of electron-dense chromatins, which are offen associated with the inner nuclear envelope, and the cytoplasm contain rough endoplasmic reticulum, several small mitochondria, and vacuoles. The primary spermatogonia have a large nuleus with a more granular electron-dense nucleoplasm. they propagate into secondary spermatogonia by the mitotic division, however, their cytoplasms are largely devoid of organelles except for scattered mitochondria (Fig. 1A).

Spermatocytes: The spermatogonium develops into the primary spermatocytes by mitotic division. At this stage, two stages of primary and secondary spermatocytes are observed in the acinus wall. Primary spermatocytes are slightly smaller cells (approximately 5.0 to $6.0 \mu \mathrm{m}$ diameter) that are distinguished by nuclei (aprroximately $3.4 \mu \mathrm{m}$ diameter) with more abundant and slightly darkly staining heterochromatin. The nucleus of the primary spermatocyte is similar in size and shape to that of the secondary spermatogonium, however, the nucleolus is no longer prominent, and the chromatins are distributed in the nucleus. Primary spermatocytes in the stages of first meiotic prophase are distinguished within the germinal layer of the testis, Zygotene/patchtene spermatocytes contain nuclei with more highly condensed chromatin and synaptonemal complexes. The synaptonemal complexes in the nucleus appear in the prophase during the first maturation division. cellular outlines are oval in shape (Fig. 1B). Primary spermatocytes differentiate into secondary spermatocytes by the meiotic division of primary spermatocytes. At this stage the secondary spermatocytes are rarely observed because of the rapidity of the first meiotic division of the primary spermatocytes. They are irregular in shape and range from about 4.5-5.5 $\mu \mathrm{m}$ in size. Spherical nucleus possess scattered chromatin forming a network. Secondary spermatocytes are frequently observed undergoing mitotic division, and the sizes of secondary spermatocytes become smaller than those of the primary spermatocytes. At this time, several accessory cells are present near several primary and secondary spermatocytes, and a large quantity of glycogen particles, several mitochondria and a few lipid droplets are present in the cytoplasm of the accessory cells (somatic cells). In particular, the accessory cells are distributed within acinal subcompartments in close association with developing germ cells (Fig. 1C).

Spermatids: During the testicular development, the secondary spermatocyte develops into the spermatids by the secondary meiotic division. For convenience, spermiogenesis divide arbitrarily into two stages: the early and late stages. In the early stage of spermatid (approximately 3.5-4.0 $\mu \mathrm{m}$ diameter), the nucleus show spherical or oval in shape and occupied the center of the cell. Nuclei of spermatids (about 2.8-3.0 $\mu \mathrm{m}$ diameter) contain electron-dense heterochromatin materials in the nucleus, and the cytoplasm contains a number of mitochondria and the Golgi complex (Fig. 1D). Based on the characteristics of cell organelle differentiation, the prossesses of acrosome formation of the spermatids occur during spermiogenesis as follows. In the late stage of spermiogenesis, the morphology of the spermatid nucleus changes gradually during the differentiation of the spermatid. At this time, small granules, which are formed by the Golgi complex in the cytoplasm, move to a position just in front of the nucleus, while mitochondria moved to a position just behind the nucleus (Fig. 1E). After all, the morphologies of the spermatid nuclei are slightly narrowed, and one or a few granules which are formed by the Golgi complex in the cytoplasm of the spermatid form a proacrosomal vesicle. The nuclei of spermatids are about $2.5 \mu \mathrm{m}$ diameter, a proacrosomal vesicle migrates to anterior end of the spermatid (Fig. $1 \mathrm{~F})$, where they coalesce to form a single electron-dense acrosomal vesicle. A single acrosomal vesicle locates at the presumptive anterior pole of the spermatids. The acrosomal vesicle shows initially oval in shape. Two components of the acrosomal vesicle are recognized: the ultrastructure of the acrosomal vesicle and deposit of subacrosomal materials (Fig. 2A). The processes of acrosomal vesicle formation showed very complex as follows. The acrosomal vesicle is membrane bound, consequently, become the cone-shape by way of various morphorphological changes and invaginations from initial oval shape and measures about $0.59 \mu \mathrm{m}$ long. 

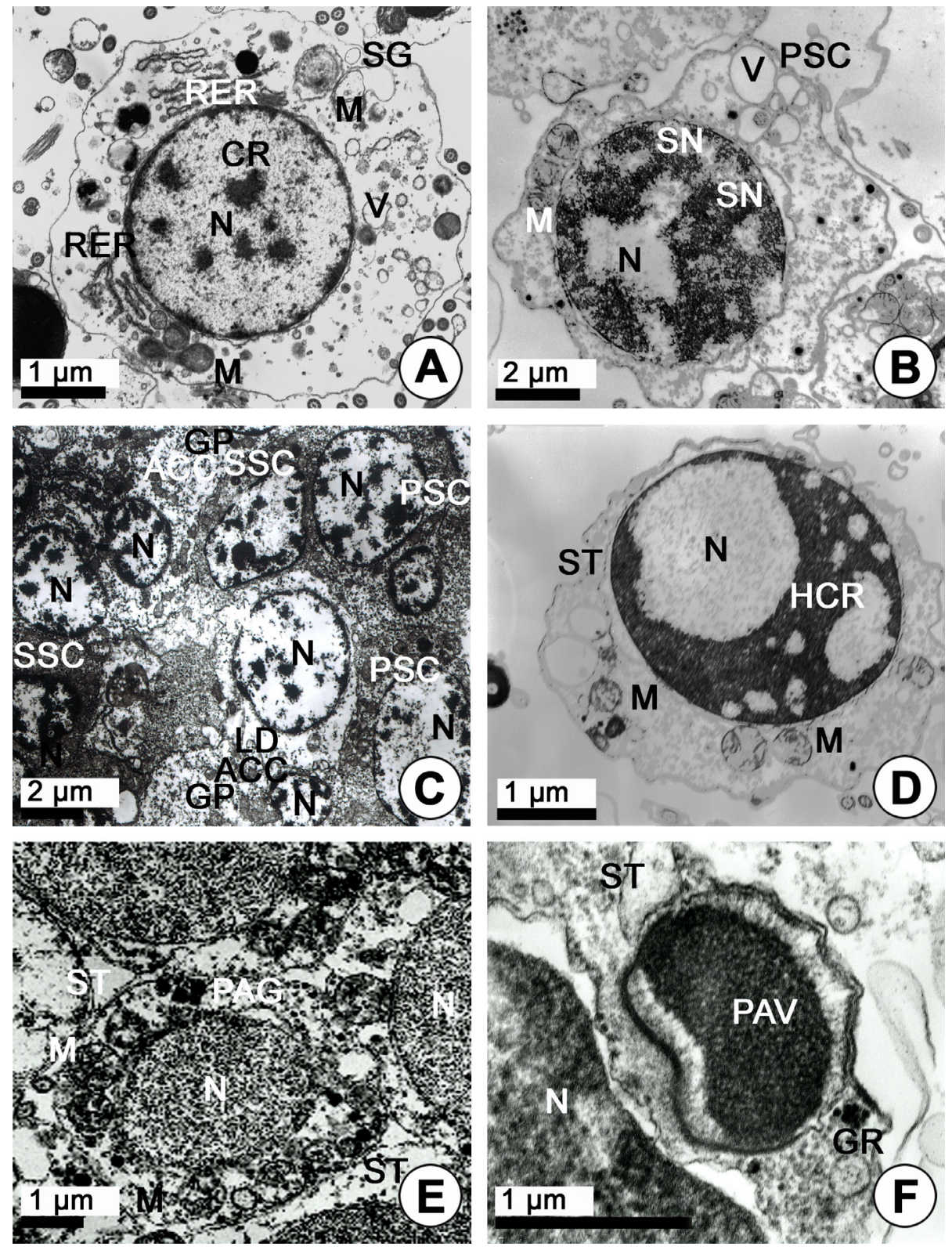

Fig. 1. Transmission electron micrographs of spermatogenesis in male Scapharca subcrenata (A-F). A: A spermatogonium (SG). Note a nucleus (N) containing chromatins (CR) in the nucleus and several mitochondria $(M)$ and vacuoles $(V)$ in the cytoplasm. B: A primary spermatocyte (PSC). Note several synaptonemal complexes $(\mathrm{SN})$ in the nucleus during the prophase of first meiotic division and mitochondria (M) in the cytoplasm. C: Primary spermatocytes (PSC), secondary spermatocytes (SSC) and accessory cells (ACC). Note the nuclei (N) of primary spermatocytes (PSC), secondary spermatocytes (SSC), and accessory cells (ACC) containing a large quantity of glycogen particles (GP) and a few lipid droplets (LD) in the cytoplasm. D: A spermatid (ST). Note high electron dense heterochromatin (HCR) materials in the nucleus (N) and mitochondria (M) in the cytoplasm. E: A spermatid (ST) in the early stage of spermiogenesis. Note high electron dense proacrosomal granules (PAG) on the region of the nucleus and several mitochondria $(M)$ under the nucleus $(N)$ of a spermatid (ST). F: A spermatid (ST) in the late stage of spermiogenesis. Note granule $(\mathrm{GR})$ and a proacrosomal vesicle (PAV) on the nucleus $(\mathrm{N})$ of a spermatid (ST). 

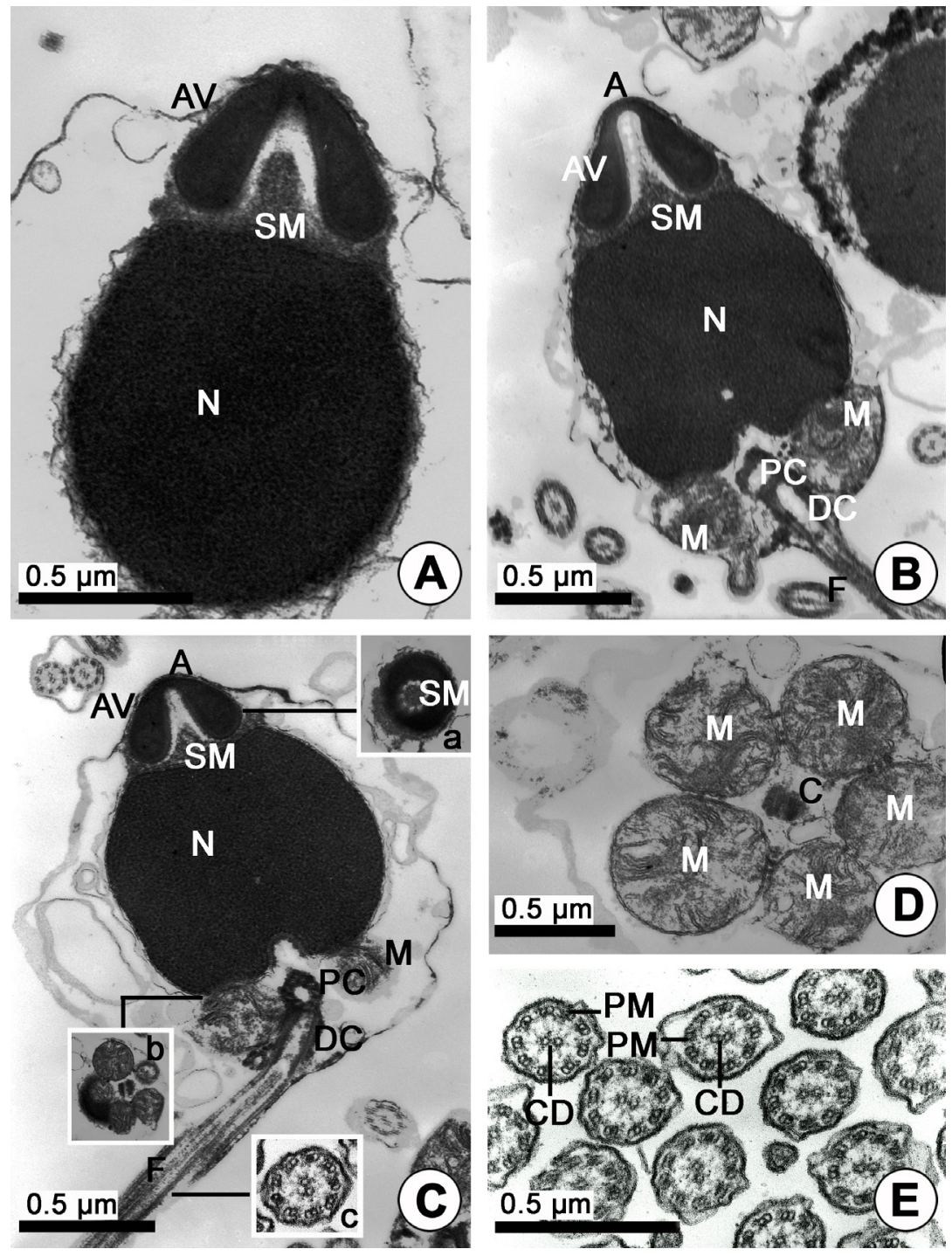

Fig. 2. Transmission electron micrographs of spermiogenesis and mature spermatozoon in male Scapharca subcrenata (A-E). A: Spermiogenesis and acrosome formation of a spermatid. Note appearance of an acrosomal vesicle $(\mathrm{AV})$ and subacrosomal material (SM) on the nucleus $(\mathrm{N})$. B: Formations of acrosomal vesicle (AV) and the midpiece of the sperm. Note subacrosomal material $(\mathrm{SM})$ in the acrosomal vesicle (AV) in the acrosome (A), 5 mitochondria $(\mathrm{M})$ and the proximal centriole $(\mathrm{PC})$ and distal centriole (DC) beneath the posterior nuclear fossa of the nucleus $(\mathrm{N})$. C: A completed matur spermatozoon with the head part, miedpiece part and the tail part. Note the head part being composed of acrosomal vesicle (AV), subacrosomal material (SM) on the sperm nucleus, the midlpiece part being composed of 5 mitochondria, the proximal centriole (PC) and distal centriole (DC), and the tail part being composed of a flagellum $(F)$. C-a: cross sectioned acrosome showing acrosomal vesicle and subacrosomal materials (SM). C-b: cross sectioned midpiece of the sperm showing 5 mitochondria. C-c: cross sectioned a flagellum. D: D: Cross sectioned sperm midpiece. Note five mitochondria surrounding a pair of centrioles (C). E: Cross sectioned tail flagellum of mature sperm. Note the axoneme showing a $9+2$ structure (a pair of central doublets (CD) and nine pair of peripheral microtubles (PM). 
The acrosomal vesicle is occupied by subacrosomal material which comprises embedded in a coasely granular matrix (Fig. 2B). However, the axial rod can not find in the subacrosomal material in the acrosomal vesicle.

At this time, in the miedpiece of the sperm, five spherical mitochondria surrounding a pair of centrioles appear and the proximal centriole and distal centriole also appear beneath the posterior nuclear fossa of the nucleus. And then a flagellum formed from the distal centriole near the satellite fibers (Fig. 2B)..

Spermatozoa: An acrosome on the nucleus is composed of acrosomal vesicles (which comprises right and left basal rings) and subacrosomal material exist in a coasely granular matrix. An acrosomal vesicle contains high electron dense opaque material from the base to the tip. In particular, the apex part and right and left lateral basal rings of an acrosomal vesicle show electron opaque part (regions), as seen in subclass Pteriomorphia species. The nucleus was oval, $1.30 \mu \mathrm{m}$ long and $1.28 \mu \mathrm{m}$ width. At this time, anteriorly the nucleus is not invaginated, this space is occupied by subacrosomal material. Posteriorly, the nucleus is invaginated into which the centrioles appear. The nuclear contents are highly electron dense (Fig. 2C). Occassional electron lucent lacunae are also visible in some sections. In the cross sectioned acrosomal vesicle, an axial rod is not present in the subacrosomal material (Fig. 2C-a). Posterior to the nucleus is the midpiece of the sperm. This region consisted of five spherical mitochondria surrounding a pair of triplet substructure centrioles (Figs. 2C-b, D). The cristae of each mitochondrion were randomly arranged, and the proximal centriole lied at $90^{\circ}$ to the sperm longitudinal axis or the distal centriole near the basal invagination of the nucleus. The distal centriole lied parallel to the sperm longitudinal axis and forms the point of origin of flagellar axoneme. satellite fibers linked the distal centriole and initial portion of the flagellum to the plasma membrane (Fig. 2C). The flagellum is composed of a $9+2$ substructure axoneme (that is, nine peripheral microtubules surrounding a central doublets) (Figs. 2C-c, E) enclosed by the plasma membrane and measures approximately 43-47 $\mu \mathrm{m}$.

\section{Spermatogenesis}

In general, spermatogenesis showed some similar phenomena to those of other bivalves (Eckelbargeret al., 1990; Eckelbarger and Davis, 1996; Chung et al., 2007; Kim et al., 2010a,b,c). Spermatogenesis occured through the interaction between germ cells and accessory cells in the acini. During spermatogenesis, the accessory cells, which was attached to germ cells in the acinus, provided nutrients for germ cell development (Eckelbargeret al., 1990; Eckelbarger and Davis, 1996; Chung et al., 2007).

In this study, during the process of spermatogenesis of germ cells, the synaptonemal complexes in the nucleus of the primary spermatocyte appeared in the pachytene stage in the prophase during the first maturation division. Commonly, it was easy to observe that the pachytene stage in the primary spermatocyte was characterized by the presence of synaptonemal complexes in the nucleus.

Recently, Sousa et al., (1989) suggested that the Golgi complex may form only a single acrosomal vesicle in a manner similar to other molluscs. As seen in the spermatid stage in Perna perna (Bernard and Hodgson, 1985) and Pecten maximus (Dorange and Le Pennec, 1989), in this study, a proacrosomal vesicle in $S$. subcrenata appeared in the spermatid stage, and this vesicle developed to an acrosomal vesicle and became an mature acrosome.

In this study, morphologies and sizes of the sperm acrosomes in Arcidae species showed similar morphological and ultrastructural characteristics, as seen in other family species. In general, the acrosome could be classified into five shapes: cone, long cone, modified cone, cap, modified cap shapes. In this study, of Arcidae species, the acrosomal morphologies of the sperms of $S$. subcrenata were a cone shape. however, of the species in Veneridae, C. sinensis and Phacosoma japonicus were the cone shape, and Saxidomus japonicus, Meretrix lusoria, Notochione jedoensis were the cap shape (Kim, 2001).

\section{Taxonomic value of sperm morphology and ultrastructure}

Ultrastructures of the spermatozoa in 5 subclasses of the bivalves have some differences in the morphologies and positions of the acrosomes of the sperms (Popham,

\section{DISCUSSION}


1979). Recently, sperm ultrastructures of bivalves and acrosomal morphology and the number of mitochondria at the midpiece of the sperm are widely used in taxonomic analyses (Healy, 1995; Popham, 1979).

In general, the sizes of sperm nuclei could not be used in taxonomic analyses because morphological characteristics of sperm nuclei were irregular and varied with the species in the family (Healy, 1995).

To date, the morphologies of the acrosomes in many families in two subclasses (Pteriormorphia and Heterodonta) have been investigated. We have confirmed that acrosomes can be distinguisable those of genuses and families by the morphologies and positions of the acrosomes.

In general, subclass Pteriomorphia in the bivalves have a common structural characteristics of the acrosomal vesicles showing the cone-like in shape, being composed of electron high dense opaque material from the base to the tip (the apex part and the right and left lateral parts of basal rings) (Hodgson and Bernard, 1986). Taxonomically, the family Arcidae belongs to the subclass Pteriomorphia. In this study, the ultrastructure and morphology of the acrosomal vesicle of S. subcrenata showed the same common characteristics mentioned above appeared in the family in sbuclass Pteriomorphia

However, all species in subclass Heterodonta in the bivalves had a common structural characteristics of the acrosomal vesicles showing the modified cone-like in shape, being composed of high electron dense opaque materials (the base and lateral parts of the basal rings) and electron lucent materials (the apex part) (Hodgson and Bernard, 1986). Thus, the acrosomal vesicle of $S$. subcrenata (belonging to Arcidae in the subclass Pteriomorphia) had some different characteristics, unlikely the species of other families in subclass Heterodonta.

Compared this species with the morphology of the acrosomal vesicles in species of other families, the morphological, phylogenetical characteristics of acrosomal vesicles in S. subcrenata showed the presence of the cone shape during spermatogenesis. Therefore, we assume that the presence of a special acrosomal vesicle during spermatogenesis can be used as a key characteristic for identification of species of the genus
Scapharca as seen in the family Arcinidae.

Even though S. subcrenata belongs to Arcidae in the subclass Pteriomorphia, the axial rod was not found in this species, unlikely Ostreidae species (Crassostrea gigas and C. nipponica) and Mytilidae species (Mytilus coruscusin) in the subclass Pteriomorphia contained the axial rod in subacrosomal materials in the acrosomal vesicle (Kim et al., 2010a,b). The species of families in the subclas Heterodonta do not have satelite fibers. However, satelite fibers were found in the species of Arcida, Ostreidae and Mytilidae in the subclass Pteriomorphia,

Arcidae (S. subcrenata) and Ostreidae (Crassostrea gigas and C. nipponica) belong to subclass Pteriomorphia. However, there are some structural differences in the acrosomal vesicle between two families of subclasses Pteriomorphia. In particular, Crassostrea gigas and C. nipponica (Ostreidae) contained 2-3 tranverse bands at the anterior part of the acrosomal vesicle (associated with fertilization between the genus Crassostrea and genus Saccostrea) (Healy and Lester, 1991; Kim et al., 2010a). However, S. subcrenata (Arcidae) does not contain a few tranverse bands at the anterior part of the acrosomal vesicle. It is assumed that tt is one of the important differences between the ultrastructures of the acrosomal vesicles of Arcidae and Ostreidae in the subclass Pteriomorphia.

In addition, of sperm ultrastructures of bivalves, the number of mitochondria in the sperm midpiece are now widely used in taxonomic analyses (Healy, 1995). That is the reason that the number of mitochondria in the sperm midpiece tends to be stable within any given family or superfamily (Healy, 1989, 1995). Recently, some authors (Chung and Ryou, 2000; Kim, 2001; Chung et al., 2007; 2010a) described that the number of mitochondria in the midpiece of the spermatozoon were four in families Ostreidae in the subclass Pteriomorphia, and Veneridae, Solenidae, Corbiculidae in the subclass Heterodonta, however, these numbers are five in Arcidae, Mytilidae, Pinnidae in the subclass Pteriomorphia, and Veneridae in the subclass Heterodonta.

Although it is the species in the same Family, the number of mitochondria at the sperm miedpiece may be some different. Sometimes, within one species, the 
number of mitochondria in the midpiece of the sperm showed slight differences in number. In the present study, we found that there are five mitochondria in the midpiece of the sperm in S. subcrenata in Arcidae in subclass Pteriomorphia. Therefore, the number of mitochondria in the sperm midpiece were not concerned with the subclasses, however, their numbers were concerned with family or superfamily (Healy, 1995). Our results on the number of mitochondria coincide with opinions of Healy (1995).

\section{ACKNOWLEDGEMENTS}

The authors are grateful to Dr. Tae Hwan Lee, the University of Michgan, for helpful comments on the manuscript.

\section{REFERENCES}

Bernard, R.T.F, Hodgson A.N. (1985) The fine structure of the sperm and spermatid differentiation in the brown mussel Perna perna. South Africa Journal of Zoology, 20: 5-9.

Chung, E.Y, and Ryou D.K. (2000) Gametogenesis and sexual maturation of the surf clam Mactra venerifermis on the west coast of Korea. Malacologia, 42: 149-163.

Chung, E.Y., Kim, E.J,, Park, G.M. (2007) Spermatogenesis and sexual maturation in male Mactra chinensis (Bivalvia: Mactridae) of Korea. Integrative Biosci, 11: 227-234.

Chung, E.Y., Chung, C.H., Kim, J.H,, Park, S.W, Park, K.H. (2010) Ultrastructures of germ cells and the accessory cells during spermatogenesis in male Gomphina veneriformis (Bivalvia: Veneridae) on the East Sea of Korea. The Korean Journal of Malacology, 26: 51-62.

Dorange, G, and Le Pennec, M.L. (1989) Ultrastructural characteristics of spermato- genesis in Pecten maximus (Mollusca, Bivalvia). Invertebrate Reproduction and Development, 15: 109-117.

Eckelbarger, KJ., Bieler, R. and Mikkelsen, P.M. (1990) ltrastructure of sperm development and mature sperm morphology in three species of commensal bivalves (Mollusca: Galeommatoidea). Journal of Morphology, 205: 63-75.

Eckelbarger, K.J. and Davis, C.V (1996) Ultrastructure of the gonad and gametogenesis in the eastern oyster, Crassostrea virginica. II. Testis and spermatogenesis. Marine Biolology, 127: 89-96.

Franzén, A. (1956) On spermatogenesis, morphology of the spermatozoon, and biology of of fertilization among invertebrates. Zoology of Bidr Uppsala, 31: $355-482$.
Franzén, Å. (1970) Phylogenetic aspects of the mophology spermatozoa and spermiogenesis. In: Baccetti B (ed) "Comparative spermatology.". Accademia Naionale Dei Lincei, Rome, pp. 573.

Gaulejac, de J., Jenry M., Vicente, N. (1995) An ultrastructural study of gametogenesis of the marine bivalve Pinna nobilis (Linnaeus, 1758). II. Spermatogenesis. J. Moll. Stu., 61:393-403.

Hata, K. (1948) On natural occurrence of Anadara subcrenata from Nakano-Umi in 1946. Bulletin of Japanese Society Science Fisheries, 13: 248-250.

Healy, JM (1989) Spermiogenesis and spermatozoa in the relict bivalve genus Neotrigonia: relevance to trigonioid relationships, particularly Unionoidea. Marine Biology, 103: 75-85.

Healy, J.M, Lester RJG. (1991) Sperm ultrastructure in the Australian oyster Saccostrea commercialis (Iredale and Roughley) (Bivalvia: Ostreidea). Journal of Molluscan Stududies, 57: 219-224.

Healy, J.M. (1995) Sperm ultrastructure in the marine bivalve families Carditidae and Crassatellidae and and its bearing on unification of the Crasssatelloidea with the Carditoidea. Zoological Science, 24: 1-28.

Hodgson, A.N, Bernard, R.T.F. (1986) Ultrastructure of the sperm and spermatogenesis of three species of Mytilidae (Mollusca, Bivalvia). Gamete Res, 15:123-135.

Jamieson, B.G.M. (1987) The ultrastructure and phylogeny of insect spermatozoa. Cambridge University Press, Cambridge Jamieson, B.G.M. (1991) Fish evolution and systematics: evidence from spermatozoa. Cambridge University Press, Cambridge, pp. 181-194.

Jamieson, B.G.M. (1991) Fish evolution and systematics: evidence from spermatozoa. Cambridge University Press, Cambridge. pp. 181-194.

Kim, J.H. (2001) Spermatogenesis and comparative ultrastructure of spermatozoa in several species of Korean economic bivalves (13 families, 34 species). Pukyung National University $161 \mathrm{pp}$.

Kim, J.H., Chung, E.Y., Choi, K.H., Lee, K.Y. and Choi, M.S. (2010a) Ultrastructure of the testis and germ cell development during spermatogenesis in male Crassostrea gigas (Bivalvia: Ostreidae) in western Korea. The Korean Hournal of Malacology, 26: 235-244.

Kim, J.H., Chung, E.Y., Lee, K.Y. Choi, M.S. and Kim, S.H. (2010b) Spermatid differentiations during and mature sperm ultrastructure in male Crassostrea niponica (Saki, 1934) (Pteriormorphia: Ostreidae). The Korean Journal of Malacology, 26: 311-316.

Kim, J.H, Chung, E.Y., Choi, K.H., Park, K.H, Park, S.W. (2010c) Ultrastructure of germ cells during spermatogenesis and some characteristics of sperm morphology in Male Mytilus coruscus (Bivalvia: Mytilidae) on the west coast of Korea. The Korean Journa of Malacology, 26: 33-43. 
Kwun, S.M. and Chung, E.Y. (1999) Reproductive cycle of the ark shell, Scapharca subcrenata, on the west coast of Korea. Journal of Fisheries Science Technology, 2: 142-148.

Popham, J.D. (1974) Comparative morphometrics of the acrosomes of the sperms of externally and internally fertilizing sperms of the sperms of the shipworms (Teredinidae, Bivalvia, Mollusca). Cell Tissue Reseach, 150: 291-297.

Popham, J.D. (1979) Comparative spermatozoon morphology and bivalve phylogeny. Malacological Review, 12: 1-20.

Sousa, M, Corral L, Azevedo C. (1989) Ultrastructural and cytochemical study of spermatogenesis $n$ Scrobicularia plana (Mollusca, Bivalvia). Gamate Research, 24: 393-401.
Tanaka, Y. (1954) Spawning season of important bivalves in Ariake Bay-1. Anadara subcrenata (Lischke). Bulletin of Japanese Society Science Fisheries, 19: 1157-1160.

Yoo, S.K. (1964) Biological studies on the propagation of important bivalves. 1. Growth and size of adult bivalves of the Anadara subcrenata. Bulletin of National Fisheries University of Pusan, 6: 15-20 (in Korean).

Yoo, S.K. (1977) Biological studies on the propagation of important bivalves. 5. Morphological characteristics of the ark shell, Anadara subcrenata. Bulletin of National Fisheries University of Busan, 17: 71-78.

Yoshida, H. (1953) Studies on larvae and youngshells of industrial bivalves in Japan. Journal of Shimonoseki College of Fisheries, 3: 15-18. 